\section{Do we still need financial intermediation? The case of decentralized finance - DeFi}

Do we still need financial intermediation?

Filippo Maria Renga

School of Management of Politecnico di Milano, Milan, Italy
Received 19 March 2021 Revised 13 September 2021 2 December 2021 Accepted 18 December 2021

\begin{abstract}
Purpose - Decentralized finance (DeFi), enabled by blockchain, could bring about a new financial system, where peers will interact directly, with little or no place for traditional intermediation. However, some crucial tasks cannot be left solely to an algorithm and, consequently, most DeFi applications still require human decisions. The aim of this research is to assess the role of intermediation in the light of DeFi, analysing how humans and algorithms will interact.
\end{abstract}

Design/methodology/approach - The authors based their work on a twofold qualitative methodology, first analysing publicly available secondary data, particularly from white papers and DeFi Pulse (a website providing data on DeFi solutions) and then running two focus group discussions.

Findings - DeFi does not eliminate financial intermediation, but enables it to be performed in new ways, where decentralization means that no single entity can hold too much power or monopoly. DeFi has, however, inherited risks from the underlying technologies that unintentionally facilitate illegal behaviour and can hamper the authorities' supervision. The complex duality algorithm- vs human-based actions will not be solved indisputably in favour of the former, as DeFi solutions can range from requiring algorithms to play a dominant role, to enabling greater human interaction by actively involving more people.

Originality/value - This research contributes to the emerging debate between algorithm- and humanbased intermediation, especially in relation to the standing literature on financial intermediation, where considerations made in the light of the newest theories on blockchain and DeFi are still scarce.

Keywords Decentralized finance, DeFi, Blockchain, Intermediation, Algorithm, Human, Transaction costs, Information asymmetry, Cryptocurrency, Bitcoin, Ethereum, Fintech

Paper type Research paper

\section{Introduction}

Bitcoin, cryptocurrencies, blockchains and the development of various apps can, independently or in combination, enable the emergence of a new financial system (Chen and Bellavitis, 2020), where peers will increasingly be able to carry out financial interactions and transactions in a free and direct manner (Chen et al., 2019; Cong and He, 2019). This development could result in there being only a marginal or even no role at all for central

(c) Laura Grassi, Davide Lanfranchi, Alessandro Faes and Filippo Maria Renga. Published by Emerald Publishing Limited. This is published under the Creative Commons Attribution (CC BY 4.0) licence. Anyone may reproduce, distribute, translate and create derivative works of this article (for both commercial and non-commercial purposes), subject to full attribution to the original publication and authors. The full terms of this licence may be seen at http://creativecommons.org/licences/by/4.0/ legalcode

The authors would like to express gratitude to Marco Santoriello for his research assistance in an early version of this work, and to the participants of the focus groups for their valuable contribution.

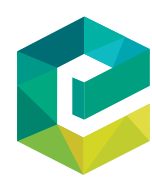

Qualitative Research in Accounting \& Management Vol. 19 No. 3, 2022 pp. $323-347$ pp. $323-347$
Emerald Publishing Limited 1176-6093 DOI 10.1108/QRAM-03-2021-0051 
QRAM 19,3 authorities or traditional intermediaries, or even to intermediation in its entirety altogether, in spite of well-established theories of financial intermediation, suggesting that intermediaries play a fundamental role in lowering transaction costs (Roth, 2015; Shiller, 2013) and in reducing information asymmetry-related issues (Biglaiser, 1993). Our findings back the position that decentralized finance (DeFi) does not eliminate financial intermediation, but enables it to be carried out in new ways, where decentralization means that no single entity can hold too much power or monopoly. DeFi has, however, inherited risks from the underlying technologies that unintentionally facilitate illegal behaviour and can hamper the authorities' supervision.

Since the release of the Bitcoin white paper in 2008 (Nakamoto, 2008) and the surge in popularity of its underlying blockchain technology, numerous startups, tech giants and major banks have started to explore the potential of these innovations, as it is particularly suited to the financial sector because of its emphasis on security and trust (Lee, 2019) and its ability to provide customized services (Thakor, 2020). Non-exhaustive examples include Facebook, which founded a global joint-venture with several partners to create a private currency denominated Libra and then renamed Diem, J.P. Morgan, which created a digital coin for interbank payments (Li et al., 2021a) and PayPal, which allows users to pay in cryptocurrency on its platform. Bitcoin is by far the most largely capitalized cryptocurrency, with more than $\$ 939 \mathrm{bn}$ in market capitalization as per February 2021 (CoinMarketCap, 2021).

Several proposals have appeared over the years. Ethereum, a "community-run technology powering the cryptocurrency, Ether and thousands of decentralized applications" (Ethereum, 2021), emerged as the main base platform to build blockchain-related financial services. Latterly, programmes not controlled by a single entity but instead running on blockchain technology, Ethereum in particular, have started to surface under the name of Decentralized Applications (Frankenfield, 2018; Li et al., 2021a), and applications of this sort for financial services are known as DeFi Apps (decentralized finance applications). The value of this new DeFi ecosystem, expressed in US dollars as the countervalue of the cryptocurrencies underlying the DeFi applications, reached a record high of $\$ 45.56 \mathrm{bn}$ on 22 February 2021, a $49 \times$ increase over the previous 12 months (DeFi Pulse, 2021). The DeFi solutions Maker, Compound and Aave locked about $\$ 18.5 \mathrm{bn}$ in March 2021, but these values are liable to change frequently because DeFi is defined by extreme volatility. Currently, there is a high correlation, of 0.89 [1], between the value of $\mathrm{DeFi}$ and Ethereum/USD, determined by its close connection to its underlying chain.

The disruptive potential of these new decentralized financial services and their rapid development and spread have been noted by regulators, with the purpose both of understanding and regulating this new market and of including its potential in their regulation and public policies, including monetary provision. The Financial Stability Board (Financial Stability Board, 2019) was among the first attempts to shed light on this phenomenon by defining how technologies can decentralize and disintermediate the new financial system. In 2019, the European Central Bank launched a call for papers to contribute to the strategic debate on the opportunities provided by DeFi and on its impact over the financial system (European Central Bank, 2019). More recently, President Lagarde declared that "The euro belongs to Europeans and we are its guardians. We should be prepared to issue a digital euro, should the need arise" (ECB, 2020, Press Release). The European Central Bank is not the only institution debating on $\mathrm{DeFi}$, as at least $80 \%$ of the main central banks worldwide have been engaging in some work regarding Central Bank Digital Currencies (CBDC) (Boar et al., 2020).

Analyses by regulators highlight opportunities, such as the reduction of concentration and solvency risks (Financial Stability Board, 2019), but also point out potential drawbacks, particularly those linked to the automatization of tasks performed by the algorithms 
underlying blockchain-based solutions. Algorithmic monetary policy, for example, could reduce the accountability of institutions in the event of bankruptcy and preclude a certain level of discretion, which is instead essential when dealing with economic shocks (Claeys et al., 2018; Bullmann et al., 2019). In the financial services provision market, some crucial tasks cannot, even in theory, be left to the sole judgment of an algorithm (Harwick, 2021; Harwick and Caton, 2021). To function, most DeFi applications still require human decisions, for example, in the development and choice of risk models (Harwick and Caton, 2021) or interest rate models [see e.g. Compound (2019)]. The specific way in which these two components - algorithms and humans - act in the provision of decentralized financial services has not yet been addressed, to the best of the authors' knowledge.

In a broad sense, the decentralization of financial services is referred to as the elimination or reduction - of the intermediation and centralized processes that have traditionally been involved in the provision of financial services (Financial Stability Board, 2019). Discussions arguing for a reduction in financial intermediation had already emerged in the 1990s, but empirical analyses suggest that this trend may have been overstated (Schmidt et al., 1999), especially in the absence of crucial enabling technology (Zavolokina et al., 2016).

The aim of this paper is to assess the role of intermediation in this new ecosystem and in a broad sense whether intermediation per se will still retain a role, while also analysing how humans and algorithm-based interventions will interact and combine. In this way, our purpose is to contribute to the emerging debate between algorithms and human-based intermediation, in particular in relation to well-established literature on financial intermediation and the newest theories on blockchain and DeFi.

\section{Theoretical background}

This section presents the main concepts of blockchain and DeFi, presenting the academic debate on the role and existence of financial intermediation following this disruptive innovation (Baur et al., 2015) and making some observations and thus opening new viewpoints, on the human-algorithm dialectic in such a context. We will start with a general discussion on the role of new technologies in shaping traditional financial activities, such as intermediation and then move on to discuss Bitcoin, the first blockchain and Ethereum, the second by market capitalization and the blockchain of preference underpinning DeFi.

\subsection{Digital innovation in finance}

Digital innovation and the development of new technologies provide the basis for improvements in the real economy (Allen and Gale, 1999), which, in turn, influences and is influenced by financial innovation (Boyd and Smith, 1996).

Financial innovation has recently become double-tied with technology and data. Fintech startups, Big Techs and even incumbents from non-financial sectors constantly leverage on huge amounts of heterogeneous data and analytics, creating new and more suitable products, improving the accurateness of pricing, lowering the costs of the intermediation process and introducing new business models (Gomber et al., 2017; Frost et al., 2019; Jagtiani and Lemieux, 2019).

Emerging new business models and technological developments (Linton, 2018; Yip and Bocken, 2018) evolved from simple tools (Gomber et al., 2017) to revolutionizing instruments for finance and insurance, especially in the case of blockchain Guo and Liang (2016) and distributed ledgers (Wüst and Gervais, 2018). As a consequence, the time span for each transaction has shortened, as some applications are executed more or less instantaneously (Ahmed and Ten Broek, 2017), the need for communication and interaction among actors has reduced (Kshetri, 2018), the barriers of geographical distance have collapsed (Swan and 
QRAM 19,3

\section{6}

De Filippi, 2017), financial information is more readily available (Coval and Thakor, 2005) and information is registered more or less immediately (Toapanta et al., 2019). The result is greater availability of free and open information, higher throughput (Novo, 2018), better perception of the sustainability of the financial ecosystem and an overall weaker intermediation function for financial institutions as the outcome of technological innovation, in a repeat of what had happened before in other sectors [e.g. e-commerce; see Chircu and Kauffman (1999)].

Although technological innovation in the financial sector has brought about remarkable changes to financial services and products (He et al., 2021), promises of increased efficiency concerning the traditional intermediaries do not always materialize (Lanfranchi and Grassi, 2021).

\subsection{Bitcoin, ethereum and blockchain}

Blockchain is thought to be among the biggest innovations of this century (Li et al., 2021b) and cryptocurrencies are seen "as a marvel of technological financial products" (Umar et al., 2021).

In 2008, a white paper on Bitcoin Nakamoto (2008), a newly minted term, a coin "based on" bits, made a significant impact on the market. As a "digital representation of value [...] which in some circumstances can be used as an alternative to money" (European Central Bank, 2015), Bitcoin was just the first evidence of new coins, cryptocurrencies and applications which have taken centre stage ever since (Ahluwalia et al., 2020). The underlying technology supporting Bitcoin has been given the name blockchain, leveraging on a structure based on different interconnected blocks (a chain), the storing place for historical transactions and information (Weber, 2016; Böhme et al., 2015).

The innovation was not merely technological as a new paradigm began to take hold. Blockchain, with - as the name implies - its chain of blocks, unveiled an infrastructure where a secure and univocal common ledger contains information and data without, theoretically, the need for any central authority or intermediary (Crosby et al., 2016). Users entering the network are given a private key, which gives them control over their own account and a public address, which identifies the account in the network. Anonymity is a major factor, as users do not have to reveal their real identity, although complete privacy is not guaranteed because of the blockchain's intrinsic transparency (Chen and Bellavitis, 2020). It is possible for users to issue cryptographically secured transactions by creating a transaction-specific digital signature and using the counterparty's public address as a transfer destination. Transactions are validated by the nodes through consensus mechanisms, where the nodes are required to solve a mathematical problem (Selgin, 2015) and are then grouped in blocks forming a chain in a specific order that ensures the security and integrity of the ledger (Eyal, 2017), making it almost impossible to delete or alter past transactions. Every validated transaction in the blockchain remains visible to everyone (Ali et al., 2014), along with a transparent and intrinsically valid historical transaction log (Hawlitschek et al., 2018), thereby allowing tracking and auditing operations (Schmitz and Leoni, 2019).

Ethereum emerged in 2015 as an alternative to Bitcoin. Ethereum is an infrastructure for implementing smart contracts (Gudgeon et al., 2020), which are contracts with predefined terms and conditions (Dong et al., 2018; Meralli, 2020; Tien et al., 2020), that are selfexecuting and have no need for central organizations (Yang et al., 2020). These characteristics enable information to be shared (Notheisen et al., 2017), facilitating micro transactions (Beck et al., 2018) and reducing the complexity of drafting contracts (Davidson et al., 2016) and hence decreasing information asymmetry and transaction costs. Smart contracts can be used for a wide range of digital assets (Chen, 2018), creating tokens that can 
either be fungible tokens, which are divisible and undistinguishable (Regner et al., 2019) or non-fungible tokens, which are unique (Westerkamp et al., 2020). A blockchain, therefore, provides the means to execute processes in a trustworthy manner even in a network where no mutual trust has been or needs to be established (Mendling et al., 2018), facilitating the way information can be viewed and compared (Saberi et al., 2019) and removing the need for assessing the trustworthiness of the other participants in the network (Nofer et al., 2017). Trust is a pivotal topic when dealing with transactions, as trust is the "key building block of society" (Mazzella et al., 2016, p. 24) and so plays an essential role in establishing interactions and relationships. Blockchains, hence, can limit the need for intermediation in financial transactions (Chen and Bellavitis, 2020). Financial service providers have been reflecting on the effect that blockchain could have for the financial system, where a core discussion concerns whether one or more intermediaries that were traditionally involved in the provision of financial services will retain any meaningful role and if so, how that role will possibly be shaped (Financial Stability Board, 2019). This technology could lead to the reframing of the finance sector, for decades reliant on the existence of central authorities to carry out crucial tasks and on a plethora of intermediaries (Ali et al., 2020).

\subsection{Decentralized finance and the role of algorithms and humans}

Enabled by smart contracts, DeFi burst onto the scene in 2018. DeFi is about the creation of an alternative financial system, where anyone, anywhere, can access financial services (e.g. lending, insurance, investment) based on digital assets (Gudgeon et al., 2020). This ecosystem of financial applications relies and is built on top of a given public blockchain Kumar et al. (2020), often Ethereum, as smart contracts are the fundamental building blocks of DeFi (Gudgeon et al., 2020). Such a DeFi-based alternative financial system involves more decentralization, innovation, interoperability, borderlessness, transparency (Chen and Bellavitis, 2020; Tien et al., 2020), security and integrity (Gudgeon et al., 2020).

These features are even more relevant when dwelling on the nature of a complex network of humans and algorithms, such as a blockchain. As "the operations of decentralized finance tend to rely primarily on the rule of code rather than human judgments" (Chen and Bellavitis, 2020), the review, auditing and formal verification of the coding tend to be even more relevant in DeFi (Tien et al., 2020). However, the answer to who is going to review, audit and verify, should it be a human or another algorithm, is not yet clear. Smart contracts have the power to run and control the ecosystem "algorithmically and - potentially - entirely without human intervention" (Harwick and Caton, 2021; Diedrich, 2016), but the absence of external enforcement of such contract, which is the role of lawyers, police, judiciary and any related body (Ammous, 2015), raises concerns about rigidity, inflexibility and accountability (Chen and Bellavitis, 2020). Moreover, in the cases where the condition for executing the smart contract relies on data coming from outside the blockchain (e.g. the weather), critical considerations come into play (Werner et al., 2021), widely referred to as the "Oracle Problem" (Hu et al., 2019): should it be a human, a network of humans or algorithms interconnected with the application which provides timely indications. This question implies the centrality of an actor providing external real-world information and taking the formal decision that will lead to the execution of a smart contract. On the one side, it opens privacy issues when the information provided has to be linked to the identity of one of the human counterparties or legal entities in any transaction (Harwick and Caton, 2021). On the other, there is the risk of the outcome being manipulated, as a network of humans might collude instead of cooperating (Klages-Mundt et al., 2020). An ex ante decision on the algorithm is then required about what kind of actor and what type of mechanisms will be chosen and established to avoid these risks, thus calling for human intervention once again. 
QRAM 19,3

It is a different matter for pure blockchain-based data, where no external intervention is needed.

Additionally, the privacy of humans in the network hides behind (and crucially is a feature of) the solid transparency of the blockchain and openness of its transaction information (Yang et al., 2020) and this could translate into DeFi applications which, in turn, inevitably evolve towards a more user-centric approach (Chen and Bellavitis, 2020).

\section{8}

\subsection{Effect of decentralized finance on intermediation}

When analysing the role and function of intermediation in the light of DeFi, the academic consensus gets weaker. A first academic stream maintains that DeFi will bring about the elimination of the intermediation function, leading to the full "democratization" of finance [Zetzsche et al. (2020)]. The second stream is instead more focused on the substitution effect of financial intermediaries.

The first stream of literature identifies disintermediation as a core feature of $\mathrm{DeFi}$, where there is no need to involve an intermediary or trusted third-party (Kumar et al., 2020; Angeris and Chitra, 2020; Ahluwalia et al., 2020), as trust is now inserted within the protocols and infrastructure and the role of a central authority is consequently not required (Ali et al., 2020). This stream is geared towards disrupting the incumbent financial institutions, particularly those that are very large, reminiscent of the "too-big to-fail" issue at the heart of the 2008 financial crisis (Zetzsche et al., 2020). DeFi also includes a kind of egalitarianism view of the financial system, with a fascination for the absence of intermediation (Wong and Eng, 2020).

With blockchain as the enabler, entrepreneurs and innovators have recognized the possibility of creating an open financial system where financial institutions have limited or no involvement (Chen and Bellavitis, 2020). In a financial setting, blockchain technology can eliminate the need for a trusted third party (Ammous, 2015) through distributed trust and decentralized platforms (Chen and Bellavitis, 2020), thus introducing peer-to-peer (P2P) transactions (Yang et al., 2020). The entire transaction process is carried out directly by the participants, decentralizing and simplifying the process itself and improving its efficiency (Yang et al., 2020). It would seem that eliminating financial intermediation in most financial industries is theoretically possible.

The second academic literature stream focuses, instead, on the substitution effect of intermediaries. Kumar et al. (2020) suggest that, in a DeFi setting, third parties such as banks or exchanges will be replaced by cryptocurrency wallets and smart contracts, which could assume the role of traditional central counterparty clearing houses and other intermediaries (Schär, 2021). Perlman (2019) also mentions that, in a DeFi system, traditional actors would be substituted by decentralized actors or, at very least, would have to disrupt their business model internally by pushing to become decentralized versions of their centralized business models and processes.

This dilemma stands unsolved, in spite of solid theory of financial intermediation dating back 50 years. Additionally, there is no overall clearness on DeFi in academic literature, in particular when it comes to evaluating the relationship between financial intermediation and DeFi and the complex duality between algorithm- and human-based actions in this context. Alongside the lack of theoretical considerations, empirical analyses of the current context are also scarce. Hence, the overall objective of this paper is to carry out an empirical investigation into the role of intermediation in the light of DeFi, as summarized in the following research question:

$R Q 1$. How does DeFi affect the role and existence of financial intermediation? 
Academic literature has shown the importance of intermediation in the financial industry, with research and the understanding of its role being underpinned by theories of transaction costs and asymmetry of information (Allen and Santomero, 2001). For this reason, this research will evaluate the intermediation function by considering a real global DeFi case and presenting our results through the theoretical lenses of transaction costs and information asymmetry, providing a view of their actual impact on intermediation.

\section{Research framework}

Transaction cost theory (Williamson, 1979) maintains that the optimal organizational structure is the one that achieves economic efficiency by minimizing the cost of transactions, which include coordination costs and the cost of controlling and managing the transactions and monitoring information.

The identification and creation of central bodies in the system and from there, intermediation, follow naturally. Intermediaries play a fundamental role in reducing transaction costs and expanding transaction possibilities, connecting participants and establishing trust, (Roth, 2015; Shiller, 2013), making it easier to match buyers with sellers (Rubinstein and Wolinsky, 1987) and reducing adverse selection by acting as quality guarantors (Biglaiser, 1993). Said otherwise, transaction costs go along with information asymmetry and together can explain intermediation (Leland and Pyle, 1977). For centuries, financial intermediaries (e.g. market makers, dealers, financial aggregators, insurance companies) have played a significant role in mediating and structuring economic transactions, otherwise difficult to execute (Benston and Smith, 1976; Akerlof, 1970; Williamson, 1981). Without intermediation, it could be impossible for transacting parties to establish connections and negotiate contracts (Chen and Bellavitis, 2020). By engaging in producing and spreading information, brokering, monitoring, providing liquidity, pooling savings, risk management and other operations, financial intermediation was able to reduce transaction costs and information asymmetry (Merton, 1995).

As intermediation finds its roots in transaction costs and asymmetry of information, we set up the theoretical lenses to develop our research framework by combining different bodies of literature on transaction costs and asymmetry of information and recent technological innovation in financial markets, namely, DeFi. In particular, we have leveraged on Rindfleisch and Heide (1997) with regard to the overarching scheme for the analysis of types of transaction costs (Table 1). Rindfleisch and Heide (1997) identified three main constructs, asset specificity, environmental uncertainty and behavioural uncertainty. Asset specificity refers to site specificity, physical specificity and human-asset specificity, temporal specificity, brand names and dedicated assets (Williamson, 1991), all of which are not relevant when considering DeFi features. Environmental uncertainty deals with exogenous events and dynamism and is associated with the direct costs of communicating new information, renegotiating agreements or coordinating activity to reflect new circumstances, as well as the work to adapt contractual agreements (Rindfleisch and Heide, 1997). Behavioural uncertainty concerns the difficulties associated with monitoring and assessing the contractual performance of counterparties

\begin{tabular}{lll}
\hline & Environmental uncertainty & Behavioural uncertainty \\
\hline Direct costs & Communication, negotiation and coordination costs & $\begin{array}{l}\text { Screening and selection costs (ex ante) } \\
\text { Measurement costs (ex post) }\end{array}$
\end{tabular}

Source: Adapted from Rindfleisch and Heide (1997)
Do we still need financial intermediation? 
QRAM 19,3

(Williamson, 1985), both ex ante and ex post, because of asymmetry of information (Rindfleisch and Heide, 1997). Ex ante asymmetry affects one party's (in)ability to screen and assess the validity of their counterparty and so the selection and gathering of information, while its ex post effects relate to the quality of the performance, the measurement of outputs or behaviour (Eisenhardt, 1985) and its enforcement.

Nevertheless, there were possible drawbacks of intermediaries, such as concerns relating to monopoly and power (Chen and Bellavitis, 2020) or single points of failure problems that could leave the whole system vulnerable (Dong et al., 2018). Historically, the alternative to intermediaries was hard to fix as it implies either duplication of effort, in the event that each entity has to monitor its counterparty constantly, or a free-rider problem, in which case no entity does any monitoring at all (Diamond, 1984). So far, there was no possibility to trace performing financial markets without relying on financial intermediation. Recently, the emergence of blockchain and DeFi show that "for the first time in human history, two or more parties, be they businesses or individuals who may not even know each other, can forge agreements, make transactions and build value without relying on intermediaries" (Tapscott and Tapscott, 2017).

The rest of the paper will use the above framework to analyse and discuss how DeFi affects financial intermediation. The methodological approach adopted to derive the results is first presented in the next section.

\section{Methodology}

To give an answer to our research question, we selected a twofold methodology, involving first the analysis of documents and then focus group discussions. We opted for an overall qualitative methodology coherently with the nature of our research questions. The two phases are combined to obtain relevant and detailed information on each DeFi service available at world level, iteratively moving from academic research to DeFi content and to practical business perspectives.

Document analysis, the first phase, has increasingly been used over the years, mainly in combination with other qualitative research methods, as a mean of triangulation (Bowen, 2009). The documents considered were prepared without the researchers' intervention (Bowen, 2009) and were not prepared specifically for this research.

Focusing on $\mathrm{DeFi}$, we conducted a document review of publicly available secondary data (Antikainen et al., 2010), leveraging on DeFi Pulse and its list of DeFi projects globally. As blockchains and DeFi services are shrouded in anonymity and collaboration, there is no way to collect first-hand primary data or to arrange interviews with the founders. First, we focused on white papers, as in the context of blockchains, they are the main outlet through which developers report detailed business information, including market prospects, functions and performance of the blockchain product (Liu et al., 2020; Adhami et al., 2018). Their analysis is "an important way to fully evaluate blockchain products" (Liu et al., 2020) and they proved to be a crucial source of information (Zhang et al., 2019; Feng et al., 2019). We also used DeFi Pulse (defipulse.com) to triangulate information. DeFi Pulse provides enough detail to identify all the relevant DeFi solutions worldwide and proposes the latest analytics and rankings of DeFi protocols. Additionally, DeFi Pulse is a frequently cited website, considered to be a kind of reference in the segment (also see Angeris and Chitra, 2020) and cited in almost any news on DeFi (Kruppa and Murphy (2019)). Considering the nature of white papers and information in DeFi Pulse, the main limitations of a document review set out by Bowen (2009) did not affect this research. There was maximum detail, the documents could be retrieved relatively easily (documents were downloaded manually from each website and DeFi Pulse) and we had no particular bias in selecting which documents to 
download, as the white papers covered all relevant and essential aspects. The representativeness of the cases analysed is optimal, as they consider all the DeFi projects originating anywhere in the world so far.

The second phase was based on a focus group and its findings. In line with previous studies on innovation in the financial sector (Santoso et al., 2021; Suryono et al., 2021), focus groups can bring synergy from multiple experiences and perspectives (Sumarwan et al., 2021), allowing participants to exchange ideas and enrich the discussion, while enabling researchers to make comparisons between different understandings and contributions (Agyemang et al., 2017). Hence, we held two focus group discussions to share and discuss the relevance of the research objective and address the validity and reliability of the preliminary findings. The focus group was heterogeneous in its composition because the aim was not to promote consensus, but rather to explore diversity in points of view and investigate critical issues on a topic where there is still no consensus (Morgan, 1996), to maximize heterogeneity and potentially, alternative perspectives and comprehensive insights (Meralli, 2020). In establishing the focus group, we included different kinds of corporations, i.e. banks, insurance companies, consultancy firms, Fintech and Insurtech startups, technological infrastructure providers and relevant companies of non-financial sectors - e.g. automotive and energy. The heterogeneity extended to the participants' background, position and seniority, although we were careful to involve highly knowledgeable participants as a means to mitigate the likelihood of biased results (Nilsson and Öhman, 2012). We thus brought in C-level managers, partners, consultants, innovation experts (e.g. heads of innovation, innovation managers), technology experts (e.g. Head of Master Data, Lead Data Scientist), business experts (e.g. Product Manager Banking, Head of Finance and Insurance) and legal experts (e.g. Legal Counsel). The objective was to give a range of views from the practical to the more strategical. Table 2 gives an overview of the people taking part in the focus group meeting.

This focus group of experts in the sector provided in-depth information through interactive discussions and the investigating of complex topics (Moretto et al., 2019). The focus group held two meetings, which served two different purposes. The first meeting, held during the design phase of this research, was to confirm the relevance of the research objective. In the second meeting, the goal was to address the validity and reliability of the preliminary findings of our document review with key informants in the industry, discussing the implications of several DeFi services.

The first focus group discussion concluded with general agreement for the forwardlooking direction of our research objective, as suggested, among others, by the Head of Innovation at a major Italian Bank, who pointed out that, while DeFi is not yet widespread, we can expect advancements concerning the management of the various aspects of finance. This position encouraged us to continue with our experimentations and business cases. With everyone in agreement, the Microsoft Teams meeting concluded after about one and a

\begin{tabular}{lclr}
\hline Business & $(\%)$ & Role and seniority & $(\%)$ \\
\hline Insurance company/broker & 23 & C-level manager and partner & 29 \\
Consultancy firm & 20 & Innovation expert & 21 \\
Bank or another financial intermediary & 18 & Business expert & 21 \\
Technological infrastructure provider & 18 & Manager and consultant & 20 \\
Fintech and Insurtech startup & 16 & Technology expert & 9 \\
Company of non-financial sector & 5 & Legal expert & 1
\end{tabular}

Do we still need financial intermediation?

Table 2.

First focus group meeting, 82 participants 
QRAM 19,3

\section{2}

Table 3.

Focal points

discussed at second

focus group meeting half hours. All the participants joined in the discussion, either by speaking out, writing in the chat stream or using icons to agree or not with someone else's idea, or by sending us feedback in the days after the meeting. Discussions from this focus group session highlighted the opportunity to look carefully at the segment of lending, among other points, in relation to $\mathrm{DeFi}$.

The second focus group discussion was primarily intended to address the validity and reliability of the preliminary findings of our document review. The meeting lasted 3 hours, with a good level of interaction and provided insightful responses to our findings. Most participants joined the second meeting and the few who did not sent their apologies for agenda clashes. Consistently with previous research (Sumarwan et al., 2021), we based our work on a semistructured focus group discussion protocol and prepared a series of slides on the preliminary findings to facilitate the discussion (see Table 3 on the main topics covered). Following Nath et al. (2019), we informed the participants via email about the objective of the session well in advance, to avoid surprises, as the focal points to be discussed covered aspects ranging from technological matters to regulatory issues. Interaction, points of view and feedback created a critical and effective discussion, resulting in greater understanding and overall better contribution to the research. Two major points emerged. The first was the importance of the level of decentralization by design that DeFi applications need to have. The second was the relevance of culture, openness of view and mindset in the humans analysing this topic.

\section{Results}

As of 15 March 2021, DeFi Pulse has reported on 83 DeFi projects, primarily built on lending, decentralized exchanges (DEXs), derivatives, payments and assets ( $\mathrm{Li}$ et al., 2021a). The Appendix contains the list of all $\mathrm{DeFi}$ projects, along with their category, underlying blockchain and approximate value locked in USD[2]. As mentioned, the projects are overwhelmingly about lending (20 projects, including peer-to-peer lending platforms or applications, providing a common resource pool where borrowers and lenders can cash in/cash out in lending transactions), DEXs (21 projects, which, for instance, provide decentralized exchanges for trading cryptocurrencies) and applications for managing financial assets (21 projects, where many providers function as automated asset managers). Surprisingly, while blockchains are used very commonly in the payment sector, with by far the most use cases (Ali et al., 2020), including payments through cryptocurrencies, they featured in only six DeFi projects. In our view, this is not an inconsistency, as, while DeFi does leverage on blockchain, it expands more towards complex use cases than simple payment transactions.

\subsection{Effect of decentralized finance on intermediation}

We mapped each DeFi project (Table 4), considering both our research framework (Column 1) and the theoretical lenses we had adopted. For each case, we will discuss the theoretical underpinning of each operation in the context of transaction cost theory and asymmetry of

\begin{tabular}{ll}
\hline Order of discussion & Focal point \\
\hline 1 & Introduction \\
2 & DeFi and decentralization \\
3 & DeFi and disintermediation \\
4 & DeFi and financial sectors \\
5 & DeFi benefits, risks and human role \\
6 & DeFi technologies and algorithms \\
\hline
\end{tabular}




\begin{tabular}{|c|c|c|c|c|}
\hline $\begin{array}{l}\text { Research framework } \\
\text { (adapted from } \\
\text { Rindfleisch and Heide, } \\
\text { 1997) }\end{array}$ & $\begin{array}{l}\text { Theoretical lenses } \\
\text { (transaction costs, } \\
\text { asymmetry of } \\
\text { information) }\end{array}$ & Selected DeFi cases & $\begin{array}{l}\text { DeFi intermediation } \\
\text { function }\end{array}$ & $\begin{array}{l}\text { Do we still need } \\
\text { financial } \\
\text { intermediation? }\end{array}$ \\
\hline \multirow[t]{6}{*}{$\begin{array}{l}\text { Environmental } \\
\text { uncertainty }\end{array}$} & $\begin{array}{l}\text { Intermediaries can } \\
\text { perform operations such } \\
\text { as purchasing securities } \\
\text { at a lower cost than } \\
\text { through direct and } \\
\text { individual channels } \\
\text { (Benston and Smith, } \\
\text { 1976), due in particular } \\
\text { to economies of scale }\end{array}$ & $\begin{array}{l}\text { "PowerPool is a } \\
\text { decentralized protocol } \\
\text { for automatically } \\
\text { managed token } \\
\text { portfolios and smart } \\
\text { indices" }\end{array}$ & $\begin{array}{l}\text { Automatization/ } \\
\text { reduction of the cost of } \\
\text { operations }\end{array}$ & 333 \\
\hline & $\begin{array}{l}\text { "The primary function } \\
\text { of any financial system } \\
\text { is to facilitate the } \\
\text { allocation and } \\
\text { deployment of economic } \\
\text { resources" (Merton, } \\
\text { 1995) }\end{array}$ & $\begin{array}{l}\text { With YFII Finance } \\
\text { "Users can deposit } \\
\text { supported tokens into } \\
\text { DFI.money which } \\
\text { automatically transfers } \\
\text { these assets into the } \\
\text { protocol that has the } \\
\text { highest yield" }\end{array}$ & $\begin{array}{l}\text { Automatic optimization } \\
\text { of resource allocation }\end{array}$ & \\
\hline & $\begin{array}{l}\text { Transaction cost theory } \\
\text { (Williamson, 1979) } \\
\text { states that the optimal } \\
\text { organizational structure } \\
\text { is the one that achieves } \\
\text { economic efficiency by } \\
\text { minimizing the costs of } \\
\text { monitoring information }\end{array}$ & $\begin{array}{l}\text { "Robo-Advisor for } \\
\text { Yield, or RAY for short, } \\
\text { is a smart contract } \\
\text { system that utilizes off- } \\
\text { chain price oracles to } \\
\text { automatically transfer } \\
\text { your funds to the } \\
\text { lending protocol } \\
\text { offering the highest } \\
\text { yield" }\end{array}$ & $\begin{array}{l}\text { Oracle-based } \\
\text { information provision }\end{array}$ & \\
\hline & $\begin{array}{l}\text { Intermediaries reduce } \\
\text { transaction costs by } \\
\text { providing liquidity } \\
\text { (Merton, 1995) }\end{array}$ & $\begin{array}{l}\text { "Hegic options can } \\
\text { always be exercised at } \\
\text { any moment during the } \\
\text { period of holding a } \\
\text { contract due to the } \\
\text { liquidity locked inside } \\
\text { the option contract } \\
\text { itself" }\end{array}$ & Liquidity providing & \\
\hline & $\begin{array}{l}\text { A financial system } \\
\text { provides a system for } \\
\text { the exchange of goods } \\
\text { and services (Merton, } \\
\text { 1995) }\end{array}$ & $\begin{array}{l}\text { "Flexa is an instant, } \\
\text { fraud-proof payments } \\
\text { network for digital } \\
\text { assets" }\end{array}$ & $\begin{array}{l}\text { Alternative payment } \\
\text { infrastructure }\end{array}$ & \\
\hline & $\begin{array}{l}\text { Market makers lower } \\
\text { relevant information } \\
\text { costs (Benston and } \\
\text { Smith, 1976) }\end{array}$ & $\begin{array}{l}\text { "Value Liquid is an } \\
\text { automated market- } \\
\text { maker built on } \\
\text { Ethereum" }\end{array}$ & $\begin{array}{l}\text { Automated market } \\
\text { maker }\end{array}$ & $\begin{array}{r}\text { Table } 4 . \\
\text { Findings on DeFi } \\
\text { intermediation } \\
\text { function }\end{array}$ \\
\hline
\end{tabular}


QRAM

19,3

334
Research framework

(adapted from

Rindfleisch and Heide, 1997)
Theoretical lenses

(transaction costs, asymmetry of information)

Insurance companies are significant financial intermediaries, analysing risks so as to set their price properly and match properties with liabilities appropriately and so investments with liabilities, to facilitate uninterrupted development (Njegomir and Miškić, 2018)

Behaviour uncertainty

The credit rating system mitigates the problem of information asymmetry (Chong et al., 2015)

Transaction cost theory (Williamson, 1979) states that the optimal organizational structure is the one that achieves economic efficiency by minimizing the costs of monitoring information

Environmental uncertainty Behaviour uncertainty

\author{
Aggregators are \\ intermediaries that \\ enable the group \\ pooling of financial \\ securities at a much \\ lower transaction cost \\ than would be required \\ to purchase of each \\ security in the basket \\ directly and individually \\ (Benston and Smith, \\ 1976)
}

\begin{tabular}{ll} 
Selected DeFi cases & $\begin{array}{l}\text { DeFi intermediation } \\
\text { function }\end{array}$ \\
\hline
\end{tabular}

"Nexus Mutual is an open platform on Ethereum that lets members pool and share risk through a discretionary mutual (a community-owned insurance alternative)"

Decentralized insurance pooling

TrueFi offers an "automated credit rating"

"Holders of Maker's other token (MKR) govern the system by voting" and "Ratify risk parameters for new collateral types"

"Sell equity signals to Numerai Erasure Quant is a new decentralized marketplace for stock market data built on Ethereum. It allows anybody to upload signals, build a track record that anyone can verify and earn money"

\section{Badger DAO creates a "one stop app for all things Bitcoin in DeFi"}

\section{Algorithmic risk assessment}

Consensus-based risk assessment

Data quality assurance
Aggregation of products/services

Table 4. 


\begin{tabular}{|c|c|c|c|c|}
\hline \multirow[t]{5}{*}{$\begin{array}{l}\text { Research framework } \\
\text { (adapted from } \\
\text { Rindfleisch and Heide, } \\
\text { 1997) }\end{array}$} & $\begin{array}{l}\text { Theoretical lenses } \\
\text { (transaction costs, } \\
\text { asymmetry of } \\
\text { information) }\end{array}$ & Selected DeFi cases & \multirow{3}{*}{$\begin{array}{l}\text { DeFi intermediation } \\
\text { function } \\
\text { Creation of a single pool } \\
\text { as transaction } \\
\text { counterparty } \\
\text { Counterparty matching }\end{array}$} & \multirow{3}{*}{335} \\
\hline & \multirow{2}{*}{$\begin{array}{l}\text { Intermediaries reduce } \\
\text { transaction costs by } \\
\text { facilitating the matching } \\
\text { of buyers and sellers } \\
\text { (Rubinstein and } \\
\text { Wolinsky, 1987) }\end{array}$} & \multirow{2}{*}{$\begin{array}{l}\text { Uniswap "uses liquidity } \\
\text { pools instead of order } \\
\text { books" } \\
\text { "PerlinX is a } \\
\text { decentralized finance } \\
\text { interface platform, } \\
\text { allowing users to trade } \\
\text { assets of any kind with } \\
\text { each other" }\end{array}$} & & \\
\hline & & & & \\
\hline & $\begin{array}{l}\text { Transaction cost theory } \\
\text { (Williamson, 1979) } \\
\text { states that the optimal } \\
\text { organizational structure } \\
\text { is the one that achieves } \\
\text { economic efficiency by } \\
\text { minimizing the costs of } \\
\text { monitoring information }\end{array}$ & $\begin{array}{l}\text { "DerivaDEX features } \\
\text { real-time price feed" }\end{array}$ & $\begin{array}{l}\text { Real-time information } \\
\text { provision }\end{array}$ & \\
\hline & $\begin{array}{l}\text { Aggregators (such as } \\
\text { mutual funds) can } \\
\text { diversify the portfolio in } \\
\text { terms of securities held, } \\
\text { their amounts, at a } \\
\text { much lower transaction } \\
\text { cost than would be } \\
\text { required to purchase } \\
\text { each security in the } \\
\text { basket directly and } \\
\text { individually (Benston } \\
\text { and Smith, 1976) }\end{array}$ & $\begin{array}{l}\text { "Index Coop is a } \\
\text { Decentralized and } \\
\text { Autonomous Asset } \\
\text { Manager governed, } \\
\text { maintained and } \\
\text { upgraded by its active } \\
\text { community of INDEX } \\
\text { token holders" }\end{array}$ & $\begin{array}{l}\text { Decentralized Asset } \\
\text { Manager }\end{array}$ & \\
\hline
\end{tabular}

information (Column 2), showing how it affects the way in which intermediaries perform their work (Column 4). Table 2 also presents selected cases to exemplify the effect of DeFi on intermediation (Column 3).

Overall, it emerges that DeFi does not eliminate financial intermediation, but enables new ways of performing it in its function of reducing transaction costs and information asymmetry, while certain decentralized projects even assume a well-defined role as intermediaries in the financial markets.

Like more traditional intermediaries (Benston and Smith, 1976), DeFi service providers can perform many operations, at a lower cost than an individual would be charged, allowing investors to adapt to changing environmental conditions at a lower cost. In many cases, they can charge less and be more efficient, because repetitive and low added-value tasks are automated. IdleTokens are one such case, allowing users to optimize the portfolio without having to switch funds between lending protocols manually. Another is Opyn, which allows options to auto-exercise at expiry. Being able to perform operations automatically, or at least at a very low cost, may facilitate portfolio optimization through the frequent and instant 
QRAM 19,3

movement of resources towards the best investment option, as enabled by YFII Finance. For instance, aggregating several products or services in a single point is a good way to reduce the transaction costs incurred by searching for these solutions. This is the philosophy used by operators such as Vesper, which offers a suite of yield-generating products. Offering a counterparty to investors in a timely way is a further, very substantial, intermediation function and can significantly reduce transaction costs (Rubinstein and Wolinsky, 1987) deriving from screening and selection, as well as from negotiation and coordination. DeFi service providers work in two main ways. They can operate, firstly, by directly matching counterparties, see PerlinX, and secondly, by creating a common pool of resources that acts as counterparty for all the investors participating, see Uniswap. Intermediation also reduces transaction costs by providing liquidity (Merton, 1995). With regard to DeFi, several solutions are possible, such as the method proposed by Hegic, where a locked liquidity pool can be used to exercise options at any moment during the period of the user holding a contract. The provision of access to payment systems is another way to reduce transaction costs deriving, in particular, from environmental uncertainty and decentralized solutions, such as Flexa, create instant, fraud-proof payment networks for digital assets.

A first relevant way in which intermediation reduces information asymmetry is by providing a clear view of the risk profile of market entities (Chong et al., 2015), reducing transaction costs associated to behaviour uncertainty. Blockchain may play an enabling role in mitigating the negative effects of information asymmetry, such as credit rationing, by verifying and validating lending and borrowing through decentralized consensus recording (Wang et al., 2019). With DeFi, risk assessment and credit rating provision can be caried out in two main ways, algorithmically, as in the case of TrueFi, or based on participant consensus, to incorporate all information available, as in the case of Maker. Another way in which intermediation can reduce transaction costs caused by information asymmetry is to monitor information (Williamson, 1979) and its distribution. Blockchain also helps, in theory, to reduce the borrowers' incentive to provide false information to the credit system (Wang et al., 2019). In the case of DeFi service providers, this function can be carried out by featuring real-time price feeds (e.g. DerivaDEX), by leveraging on oracles (e.g. Opium) and by ensuring high standards of quality. Numerai, for example, developed a "decentralized data marketplace for predictions which allows users to upload predictions and build reputation over time by staking cryptocurrencies like Numeraire (NMR) or DAI to show their confidence in their data or prediction".

Certain decentralized intermediaries assume a well-defined role in the financial markets. Firstly, DeFi providers act as Decentralized and Autonomous Asset Managers, as is the case of Coop, providing cost savings in the same way as traditional aggregators (such as mutual funds). Their action can diversify the portfolio in terms of securities and their amounts are held at a much lower transaction cost than would otherwise be the case in the direct and individual purchase of each security (Benston and Smith, 1976). This produces a beneficial effect on transaction costs deriving both from behaviour and environment uncertainty. Secondly, DeFi provides a decentralized equivalent of insurance companies; see Nexus Mutual. Similarly to traditional insurance companies, this DeFi application performs intermediation. Examples in the third group are market makers, which traditionally facilitate the matching of buyers and sellers, by continuously standing ready to buy from sellers and to sell to buyers (Schwartz and Peng, 2013), thus lowering relevant information costs (Benston and Smith, 1976). DeFi automated market makers (AMMs) are protocols that use algorithms to price assets (see LINKSWAP and Swerve), further reducing environment uncertainty. AMMs play an important role also in reducing information asymmetry, by 
providing prices that have a signalling value, thereby delivering common information regarding the value of an asset to both buyers and sellers.

The implication of such results is of immediate relevance. Academic literature claiming that DeFi represents disintermediation or the full "democratization" of finance (Zetzsche et al., 2020) (thus leading to the elimination of intermediation in financial markets) should be properly reconsidered in the light of empirical evidence. Indeed, all $\mathrm{DeFi}$ applications perform the role of intermediary, measured in terms of capability of the provider to reduce transaction costs and/or information asymmetry. DeFi is certainly reshaping the way in which it is possible to carry out intermediation operations, while not necessarily eliminating the presence or the role of the intermediaries. Intermediation does not disappear, but is performed by someone or something different, such as platforms or codes, e.g. smart contracts (Kumar et al., 2020), programmed in such a way as to reduce transaction costs and information asymmetry.

Often "decentralization" emerges as an enabler of this transformation to the intermediation function, with many nodes taking part in the system's operation, as in any blockchain (Buterin, 2017). When shifting from a centralized to a DeFi, financial transactions cease to be facilitated by centralized institutions in favour of decentralized peer-to-peer networks (Chen and Bellavitis, 2020). According to Huberman et al. (2019), when a decentralized peer-to-peer network rises to dominance, no single entity can accumulate sufficient power to monopolize the network and exclude others from participating, allowing everybody to benefit from the network effects and to expand the transaction possibilities. Reducing the involvement of centralized parties allows decentralized networks to reduce transaction costs and create network effects (Catalini and Gans, 2019).

\subsection{Decentralized finance and the role of algorithms and humans}

DeFi impacts on the intermediation function and the way in which it relies on blockchains and algorithms rather than human intervention. Although innovative technologies may enable more algorithmic-driven actions, potentially entirely without human intervention (Diedrich, 2016), from our analysis, it emerged that DeFi also enables greater human interaction, with a larger number of people being actively engaged. DeFi does not mean removing humans from the equation, as decentralization itself may enable them to play a stronger role or, at least, lead to more people being actively involved. One example is the concept of distributed knowledge, which underpins Wikipedia (Aaltonen and Lanzara, 2015) and the involvement of a countless number of humans is the reason why Wikipedia itself is more resilient and up-to-date, as well as being cheaper to operate and access, than any encyclopaedia managed by a centralized authority (Ammous, 2015).

Algorithms can outshine humans in the automation of repetitive tasks and operations in trading activities, as in Opyn, or the automatic optimization of resource allocation, as in YFII Finance, where users deposit approved tokens on the platform and the platform automatically transfers these assets to the protocol that gives the highest yield at that time, or in automated credit rating, as offered by TrueFi. Automation is particularly easy to implement when tasks are structured and repetitive (Kokina and Davenport, 2017).

Vice versa, an interesting DeFi solution that magnifies the human function comes from Numerai. Numerai is a decentralized hedge fund for predicting the stock market, allowing users (mainly data scientists) to submit their predictions and so build up a reputation over time; they are ready to "put their money where their mouth is" to underscore their confidence in their data or predictions, hence improving data quality. Another is Maker, where Maker's token holders govern the system by voting and endorsing risk parameters for new collateral types, enabling network members to take an active part in the risk assessment process. 
QRAM 19,3

Given the intrinsic transparency of blockchain (Chen and Bellavitis, 2020) and its crucial role as the underlying technology of $\mathrm{DeFi}$, concerns have arisen about the difficulty of ensuring complete privacy. Some DeFi applications address privacy concerns directly, as for instance Tornado Cash, which uses a smart contract to accept deposits that can be withdrawn by any on-chain address (with the depositor's authorization), ensuring that there is no way to link the withdrawal to the deposit. This does shield users from the intrusiveness of other users, but potentially also from being investigated by authorities and regulators, similar to ethics in cryptocurrencies (Angel and McCabe, 2015; Dierksmeier and Seele, 2018). Hence, certain solutions that leverage solely on technologies based on algorithms, such as smart contracts, may facilitate unethical actions with unsustainable long-term consequences, e.g. money laundering, with the risk of introducing more complexity to the supervision and regulation of those markets. Dealing with privacy concerns entails the careful balancing of humans and algorithms, as the latter may be more efficient in ensuring privacy, but humans are needed to ensure compliance with regulations and matters of acceptable and sustainable conduct.

\section{Discussion}

Three main managerial implications of decentralization emerged from our results, namely, governance, record-keeping and risk-taking, thus confirming the insights gleaned from financial regulators (Financial Stability Board, 2019).

The decentralization of governance (decision-making) entails moving away from a financial system where a single or a restricted group of entities, whom are trusted by the other agents for their competency and honesty (Dwyer, 2015), are entitled to make decisions about markets and services, to a financial system where no single entity has exclusive control over the markets, services or processes through which these services are delivered. The rules of this decentralized financial system are embedded in software parameters that can be changed only if so agreed by a sufficient majority of users (Yermack, 2017). No single individual has the leadership or power to benefit personally as control is scattered, thus eliminating the presence or need for a single central trust or point of failure, at least without an unpredictable act of conspiracy [3] and guaranteeing reliability. No algorithm or human can alter the information stored or revert the flow through retrospective manipulations (Beck, 2018), or take over and shut down the system (Wang et al., 2018). This kind of decentralization is one of the most complex aspects in developing a Decentralized Financial system. Already today, several DeFi service providers are issuing tokens with voting power, enabling holders to "vote to help decide the direction of the cooperative" (e.g. Harvest), change the protocol (e.g. Pickle Protocol), approve new loans (e.g. TrueFi), ultimately causing ownership and governance power to converge (as in Badger DAO) and reducing the principal-agent problem (Jensen and Meckling, 1976).

The decentralization of record-keeping, enabled by blockchains (Ahluwalia et al., 2020), refers to a shift towards systems where the ability to store and access data is extended across broader consortia of users, thus differing from systems where data and records are held centrally. The verification of such data and records may also be more widely distributed through consensus mechanisms (e.g. Maker). DeFi derives some of its technical features from the blockchain on which it leverages. Network access is often open, enabling any human or algorithm to manage access, without the need for a central authority. However, there are potential downsides, as each entity automatically receives an address which is associated to a public and a private key and these must be kept secret and protected carefully. There is no way to regain possession of a lost key or to backtrack on mistakes arising from having revealed it and there is no way to retaliate in the event of a malicious cyberattack (Novo, 2018). 
The decentralization of risk-taking means shifting from the situation where risk is retained in the financial statements of individual traditional intermediaries to directly matching counterparties in financial transactions (Financial Stability Board, 2019). In this sense, DeFi apps decentralize risk-taking in two ways, either by creating a system-wide collateral (e.g. Maker) or by introducing decentralized risk carriers which are responsible for making a potential insurance payout (e.g. Nexus Mutual). This point has not yet been strongly recognized in the blockchain debate, precisely because it is intrinsically linked to specific DeFi characteristics and solutions. There are major implications for system stability [one of the goals of the Basel Committee is to improve the financial sector's ability to absorb shocks (Caruana, 2010)], as well as the repercussions on the risk-management strategies for each DeFi application.

\subsection{Open questions on decentralized finance, its effect on intermediation and the role of algorithms and humans}

Alongside the effects of governing a single DeFi solution, record-keeping and risk-taking, there are also other open questions and challenges, firstly about the suitability of the supervisory financial system and its stability and risk exposure:

Q1. What if the small retail investors rely on DeFi as their financial intermediary?

Q2. What happens if DeFi applications become "too big" and what happens if every DeFi solution is always based on Ethereum alone?

Q3. What happens in the event of the custodians or alternative payment infrastructures defaulting?

Q4. What happens in the event of fraud or problems in technology or in the way the underlying blockchain performs?

Q5. What if DeFi risk management solutions do not estimate risks properly?

Q6. What if we cannot recognize which investors are selecting DeFi solutions as their main investment without (them) understanding the associated risks and volatility?

Secondly, there are questions about current legal mechanisms:

Q7. What is the jurisdiction that applies in the event of a controversy (Zetzsche et al., 2020)?

Q8. What should a user do if a smart contract does not perform as it is supposed to?

Q9. Who is liable for faults, is it a human or an algorithm?

Q10. How can we pinpoint the identity of anonymous humans, in such a case?

Thirdly, there are considerations on interoperability issues between DeFi applications, as a legacy of the lack of interoperability across blockchains (Chen and Bellavitis, 2020). As we are expecting an increasing number of DeFi applications to turn to multichain arrangements and be open to direct interaction and partnerships:

Q11. Who will be the first mover to go multichain and for what reasons?

Q12. What are the benefits and risks of multichain applications? 
QRAM 19,3
Q13. What role will human relations have in establishing partnerships? And what is its relevance for algorithms and technological development?

Q14. What is a suitable context for partnerships between DeFi actors?

Fourthly, there are questions on the issue of single point of failure. As most DeFi projects integrate the same infrastructure into their services, will this create interlinkages that are relevant enough to open the door once more to systemic risks (Tien et al., 2020)?

Fifthly are the questions about the balance between algorithms and humans:

Q15. How will decentralized finance re-establish balance between algorithm- and human-based actions?

Finally are the considerations about the actual specialization of DeFi applications versus the common diversification of traditional financial intermediaries. Economies of scale from specialization, economies from diversification, economies for customers (i.e. "one-stop shop") and the likelihood of bankruptcy (Benston and Smith, 1976) are just some of the potential perspectives for discussions about DeFi.

There are clearly many avenues for further research that branch out from this work on $\mathrm{DeFi}$, its effect on intermediation and the role of algorithms and humans.

\section{Conclusions}

Financial intermediation plays a fundamental role in financial markets, by establishing trust (Roth, 2015), facilitating the matching of buyers and sellers (Rubinstein and Wolinsky, 1987) and producing and spreading information (Merton, 1995). The theoretical foundation of their role can be traced back to transaction costs and information asymmetries (Leland and Pyle, 1977). The concept of DeFi has emerged in recent years, where the term is used to identify the ecosystem of financial applications built on top of a public blockchain [Kumar et al. (2020)], often Ethereum. DeFi is about the creation of an alternative financial system where anyone, anywhere, can access financial services (e.g. lending, insuring or investing).

In this paper, we have investigated the role of intermediation in the light of DeFi and the complex duality between algorithm- and human-based actions. We mapped and analysed 83 relevant DeFi projects globally, finding that all of them contribute to reducing transaction costs deriving from either environmental or behaviour uncertainty, or both. In doing so, DeFi projects engage in intermediation activity, as identified in extant theories. From our study, it emerges that DeFi does not eliminate financial intermediation, but enables new ways of performing this function, by someone or something different, such as platforms and codes and is programmed so as to reduce transaction costs and information asymmetry. "Decentralization" emerges as an enabler of this transformation to intermediation and refers to an arrangement with multiple nodes, all of which take part in operating the system. This situation replicates that in any blockchain (Buterin, 2017), where no single entity can accumulate sufficient power to monopolize the network and exclude others from participating, allowing everybody to benefit from the network effects and to amplify the transaction possibilities. Reducing the involvement of centralized parties enables decentralized networks to reduce transaction costs and create beneficial network effects (Catalini and Gans, 2019).

Furthermore, our analysis suggests that it is too simplistic to assume that the complex duality between algorithm- and human-based actions in DeFi will be solved in favour of the former. We found that DeFi solutions can range from requiring algorithms to be given a 
stronger role, for instance, through automation, hence reducing or even eliminating human intervention, to enabling greater human interaction, with the active participation of more people. The role played by algorithms in DeFi can outshine the human role easily in structured and repetitive tasks, such as trading, resource allocation or credit rating. However, DeFi solutions magnify the role played by humans in cases involving a decentralized data marketplace or in governance systems, enabling network members to take an active part. In other cases, equilibrium concerns emerge regarding the benefits that algorithms can bring to human routines, but which may lead to actions with unsustainable consequences or risks for society, as in the case of privacy matters and anti-money laundering issues.

Several open questions and challenges also arise over the suitability of the supervisory financial system and its stability and exposure to risk and about current legal mechanisms and enforcements, as well as considerations about interoperability issues between DeFi applications, as a legacy of the lack of interoperability across blockchains. There are also concerns about the single point of failure and discussions about the actual specialization of DeFi applications versus the common diversification of traditional financial intermediaries.

The relevance of this research is threefold. From the academics' point of view, it contributes to the stream on financial intermediation, to that on blockchain and DeFi and to the emerging debate on the merits of algorithm- versus human-based intermediation. With our results, we are carefully reshaping the claims in literature where it is suggested that $\mathrm{DeFi}$ is a way to eliminate intermediation; we maintain that existing theories on transaction costs, information asymmetry and intermediation are still valid and, at the same time, we are moving the attention of future research towards the way in which DeFi could transform, not eliminate, intermediation. For authorities and policymakers, we contribute to the understanding of the role played by financial intermediaries, where DeFi can support their subsequent decisions about their next actions and regulations. We also open further considerations, listed above, on the suitability of the supervisory financial system and its stability and risk exposure, current legal mechanisms, interoperability issues between DeFi applications and the single point of failure issue. Finally, from the perspective of practitioners, we have outlined the practical implications of DeFi projects for traditional intermediaries and new innovative entrants alike (e.g. Fintech startups, new DeFi applications). The new players, especially, can be seen as an intriguing opportunity for renewal and innovation.

\section{Notes}

1. Relative to the six-month period February-July 2021.

2. Ethereum is the underlying blockchain of the 83 DeFi projects, meaning that the value locked in DeFi is computed by DeFi Pulse by taking the total balance of Ether (ETH) and ERC-20 tokens held in smart contracts relating to each protocol on the Ethereum blockchain. The USD value is obviously the corresponding value of this balance.

3. See, for instance, the Ethereum Classic blockchain 51\% attack in August 2020.

\section{References}

Aaltonen, A. and Lanzara, G.F. (2015), "Building governance capability in online social production: insights from wikipedia”, Organization Studies, Vol. 36 No. 12, pp. 1649-1673.

Adhami, S., Giudici, G. and Martinazzi, S. (2018), "Why do businesses go crypto? An empirical analysis of initial coin offerings", Journal of Economics and Business, Vol. 100, pp. 64-75. 
QRAM 19,3

\section{2}

Agyemang, G., O’Dwyer, B., Unerman, J. and Awumbila, M. (2017), "Seeking 'conversations for accountability': mediating the impact of non-governmental organization (NGO) upward accountability process", Accounting, Auditing and Accountability Journal, Vol. 30 No. 5, pp. 982-1007.

Ahluwalia, S., Mahto, R.V. and Guerrero, M. (2020), "Block chain technology and startup financing: a transaction cost economics perspective", Technological Forecasting and Social Change, Vol. 151, p. 119854.

Ahmed, S. and Ten Broek, N. (2017), "Block chain could boost food security", Nature, Vol. 550 No. 7674, pp. 43-43.

Akerlof, G.A., (1970), "The Market for 'lemons': quality uncertainty and the market mechanism”, The Quarterly Journal of Economics, Vol. 3 No. 84, pp. 488-500.

Ali, O., Ally, M. and Dwivedi, Y. (2020), "The state of play of block chain technology in the financial services sector: a systematic literature review", International Journal of Information Management, Vol. 54, p. 102199.

Ali, R. Barrdear, J. Clews, R. and Southgate, J. (2014), "The economics of digital currencies”, Bank of England Quarterly Bulletin, Q3.

Allen, F. and Gale, D. (1999), "Diversity of opinion and financing of new technologies", Journal of Financial Intermediation, Vol. 8 Nos 1/2, pp. 68-89.

Allen, F. and Santomero, A.M. (2001), "What do financial intermediaries do?", Journal of Banking and Finance, Vol. 25 No. 2, pp. 271-294.

Ammous, S. (2015), "Economics beyond financial intermediation: digital currencies' possibilities for growth, poverty alleviation and international development", The Journal of Private Enterprise, Vol. 30 No. 3, pp. 19-50.

Angel, J.J. and McCabe, D. (2015), "The ethics of payments: paper, plastic, or bitcoin?", Journal of Business Ethics, Vol. 132 No. 3, pp. 603-611.

Angeris, G. and Chitra, T. (2020), "Improved price oracles: constant function market makers", Proceedings of the 2nd ACM Conference on Advances in Financial Technologies, pp. 80-91.

Antikainen, M., Mäkipää, M. and Ahonen, M. (2010), "Motivating and supporting collaboration in open innovation”, European Journal of Innovation Management, Vol. 13 No. 1, pp. 110-119.

Baur, A.W., Bühler, J., Bick, M. and Bonorden, C.S. (2015), "Cryptocurrencies as a disruption? Empirical findings on user adoption and future potential of bitcoin and co", Conference on e-Business, e-Services and e-Society, Springer, Cham, pp. 63-80.

Beck, R. (2018), "Beyond bitcoin: the rise of block chain world”, Computer, Vol. 51 No. 2, pp. 54-58.

Beck, R., Müller-Bloch, C. and King, J.L. (2018), “Governance in the block chain economy: a framework and research agenda", Journal of the Association for Information Systems, Vol. 19 No. 10, pp. 1020-1034.

Benston, G.J. and Smith, C.W. (1976), "A transactions cost approach to the theory of financial intermediation”, The Journal of Finance, Vol. 31 No. 2, pp. 215-231.

Biglaiser, G. (1993), "Middlemen as experts", The RAND Journal of Economics, Vol. 24 No. 2, pp. 212-223.

Boar, C., Holden, H. and Wadsworth, A. (2020), "Impending arrival - a sequel to the survey on Central bank digital currency”, BIS paper, p. 107.

Böhme, R., Christin, N., Edelman, B. and Moore, T. (2015), "Bitcoin: economics, technology and governance", Journal of Economic Perspectives, Vol. 29 No. 2, pp. 213-238.

Bowen, G.A. (2009), "Document analysis as a qualitative research method", Qualitative Research Journal, Vol. 9 No. 2, pp. 27-40.

Boyd, J. and Smith, B. (1996), "The coevolution of the real and financial sectors in the growth process", The World Bank Economic Review, Vol. 10 No. 2, pp. 371-396. 
Bullmann, D., Klemm, J. and Pinna, A. (2019), "In search for stability in crypto-assets: are stable coins the solution?”, ECB Occasional Paper, No. 230.

Buterin, V. (2017), “The meaning of decentralization”, available at: https://medium.com/@ VitalikButerin/the-meaning-of-decentralization-a0c92b76a274 (accessed 30 July 2021)

Caruana, J. (2010), “Systemic risk: how to deal with it?”, BIS, available at www.bis.org/publ/othp08.htm

Catalini, C. and Gans, J.S. (2019), "Rotman school of management working paper no. 2874598", MIT Sloan Research Paper No. 5191-16, available at SSRN: https://ssrn.com/abstract=2874598 or http://dx.doi.org/10.2139/ssrn.2874598, Some Simple Economics of the Blockchain.

Chen, M.A., Wu, Q. and Yang, B. (2019), "How valuable is FinTech innovation?", The Review of Financial Studies, Vol. 32 No. 5, pp. 2062-2106.

Chen, Y. (2018), "Block chain tokens and the potential democratization of entrepreneurship and innovation”, Business Horizons, Vol. 61 No. 4, pp. 567-575.

Chen, Y. and Bellavitis, C. (2020), "Block chain disruption and decentralized finance: the rise of decentralized business models", Journal of Business Venturing Insights, Vol. 13, p. e00151.

Chircu, A.M. and Kauffman, R.J. (1999), "Strategies for internet middlemen in the intermediation/ disintermediation/reintermediation cycle”, Electronic Markets, Vol. 9 Nos 1/2, pp. 109-117.

Chong, B.U., Hwang, I.D. and Kim, Y.S. (2015), "Credit ratings and short-term debt financing: an empirical analysis of listed firms in Korea”, Asia-Pacific Journal of Financial Studies, Vol. 44 No. 1, pp. 88-128.

Claeys, G. Demertzis, M. and Efstathiou, K. (2018), “Cryptocurrencies and monetary policy”, (No. 2018/ 10), Bruegel Policy Contribution.

CoinMarketCap (2021), “Today's crypto currency prices by market cap", available at: https:// coinmarketcap.com/ (accessed 25 February 2021).

Compound (2019), “Compound: the money market protocol”, available at: https://compound.finance/ documents/Compound. Whitepaper.pdf (accessed 25 February 2021).

Cong, L.W. and He, Z. (2019), "Block chain disruption and smart contracts", The Review of Financial Studies, Vol. 32 No. 5, pp. 1754-1797.

Coval, J.D. and Thakor, A.V. (2005), "Financial intermediation as a beliefs-bridge between optimists and pessimists", Journal of Financial Economics, Vol. 75 No. 3, pp. 535-569.

Crosby, M., Pattanayak, P., Verma, S. and Kalyanaraman, V. (2016), "Block chain technology: beyond bitcoin", Applied Innovation, Vol. 2 No. 6-10, p. 71.

Davidson, S. De Filippi, P. and Potts, J. (2016), “Economics of blockchain”, available at SSRN 2744751.

DeFi Pulse (2021), “The DeFi pulse index”, available at: https://defipulse.com/ (accessed 25 February 2021).

Diamond, D.W. (1984), "Financial intermediation and delegated monitoring", The Review of Economic Studies, Vol. 51 No. 3, pp. 393-414.

Diedrich, H. (2016), Ethereum: Blockchains, Digital Assets, Smart Contracts, Decentralized Autonomous Organizations, Wildfire publishing.

Dierksmeier, C. and Seele, P. (2018), "Crypto currenci es and business ethics", Journal of Business Ethics, Vol. 152 No. 1, pp. 1-14.

Dong, X. Mok, R.C.K. Tabassum, D. Guigon, P. Ferreira, E. Sinha, C.S. Prasad, N. Madden, J. Baumann, T. and Libersky, J. (2018), "Block chain and emerging digital technologies for enhancing post2020 climate markets", World Bank Group, Washington, DC, available at: http://documents. worldbank.org/curated/en/942981521464296927/Blockchainand-

Dwyer, G.P. (2015), "The economics of bitcoin and similar private digital currencies", Journal of Financial Stability, Vol. 17, pp. 81-91.

Eisenhardt, K.M. (1985), “Control: organizational and economic approaches”, Management Science, Vol. 31 No. 2, pp. 134-149.

Do we still need financial intermediation?

(1) \\ (n)}


QRAM 19,3

\section{4}

Ethereum (2021), "Welcome to ethereum”, available at: https://ethereum.org/en/ (accessed 25 February 2021).

European Central Bank (2015), "Virtual currency schemes - a further analysis", available at: www.ecb. europa.eu/pub/pdf/other/virtualcurrencyschemesen.pdf (accessed 30 July 2021).

European Central Bank (2019), "P2P financial systems 2019", available at: www.ecb.europa.eu/pub/ conferences/html/20190726_joint_ECB_UCL_P2P_workshop_CALL.en.html (accessed 25 February 2021).

European Central Bank (2020), “A digital euro”, available at: www.ecb.europa.eu/euro/html/digitaleuro. en.html (accessed 25 February 2021).

Eyal, I. (2017), "Block chain technology: transforming libertarian crypto currency dreams to finance and banking realities", Computer, Vol. 50 No. 9, pp. 38-49.

Feng, C., Li, N., Wong, M.H. and Zhang, M. (2019), "Initial coin offerings, block chain technology and white paper disclosures”, Mingyue, Initial Coin Offerings, Block chain Technology and White Paper Disclosures (March 25, 2019).

Financial Stability Board (2019), "Decentralised financial technologies: report on financial stability, regulatory and governance implications", available at: www.fsb.org/2019/06/decentralised-financial-technologiesreport-on-financial-stability-regulatory-and-governance-implications/ (accessed 25 February 2021).

Frankenfield, J. (2018), "Decentralized applications - dApps", available at: www.investopedia.com/ terms/d/decentralized-applications-dapps.asp (accessed 25 February 2021).

Frost, J., Gambacorta, L., Huang, Y., Shin, H.S. and Zbinden, P. (2019), "BigTech and the changing structure of financial intermediation”, Economic Policy, Vol. 34 No. 100, pp. 761-799.

Gomber, P., Koch, J.A. and Siering, M. (2017), "Digital finance and FinTech: current research and future research directions", Journal of Business Economics, Vol. 87 No. 5, pp. 537-580.

Gudgeon, L., Werner, S., Perez, D. and Knottenbelt, W.J. (2020), "DeFi protocols for loanable funds: Interest rates, liquidity and market efficiency", Proceedings of the 2nd ACM Conference on Advances in Financial Technologies, pp. 92-112.

Guo, Y. and Liang, C. (2016), "Block chain application and outlook in the banking industry", Financial Innovation, Vol. 2 No. 1, pp. 1-12.

Harwick, C. (2021), "Inside and outside perspectives on institutions: an economic theory of the noble lie", Journal of Contextual Economics, doi: 10.2139/ssrn.3187581.

Harwick, C. and Caton, J. (2021), "What's holding back block chain finance? On the possibility of decentralized autonomous finance", The Quarterly Review of Economics and Finance, doi: 10.1016/j.qref.2020.09.006.

Hawlitschek, F., Notheisen, B. and Teubner, T. (2018), "The limits of trust-free systems: a literature review on block chain technology and trust in the sharing economy", Electronic Commerce Research and Applications, Vol. 29, pp. 50-63.

He, X., Xiong, D., Khalifa, W.M. and Li, X. (2021), "Chinese banking sector: a major stakeholder in bringing fourth industrial revolution in the country", Technological Forecasting and Social Change, Vol. 165, p. 120519.

Hu, Y.C., Lee, T.T. and Lam, C. (2019), April), "A risk redistribution standard for practical cryptocurrency payment”, 2019 IEEE International Conference on Decentralized Applications and Infrastructures (DAPPCON), IEEE, pp. 89-99.

Huberman, G., Leshno, J.D. and Moallemi, C. (2019), “An economist's perspective on the bitcoin payment system”, AEA Papers and Proceedings, Vol. 109, pp. 93-96.

Jagtiani, J. and Lemieux, C. (2019), "The roles of alternative data and machine learning in fintech lending: evidence from the lending club consumer platform", Financial Management, Vol. 48 No. 4, pp. 1009-1029.

Jensen, M.C. and Meckling, W.H. (1976), "Theory of the firm: managerial behavior, agency costs and ownership structure", Journal of Financial Economics, Vol. 3 No. 4, pp. 305-360. 
Klages-Mundt, A., Harz, D., Gudgeon, L., Liu, J.Y. and Minca, A. (2020), "Stable coins 2.0: economic foundations and risk-based models", Proceedings of the 2nd ACM Conference on Advances in Financial Technologies, pp. 59-79.

Kokina, J. and Davenport, T.H. (2017), "The emergence of artificial intelligence: how automation is changing auditing", Journal of Emerging Technologies in Accounting, Vol. 14 No. 1, pp. 115-122.

Kruppa, M. and Murphy, H. (2019), "DeFi' movement promises high interest but high risk”, Financial Times, 30 December.

Kshetri, N. (2018), "1 Block chain's roles in meeting key supply chain management objectives", International Journal of Information Management, Vol. 39, pp. 80-89.

Kumar, M., Nikhil, N. and Singh, R. (2020), "Decentralising finance using decentralised blockchain oracles", 2020 International Conference for Emerging Technology (INCET), IEEE, pp. 1-4.

Lanfranchi, D. and Grassi, L. (2021), "Translating technological innovation into efficiency: the case of US public P\&C insurance companies”, Eurasian Business Review, Vol. 11, pp. 565-585.

Lee, J.Y. (2019), "A decentralized token economy: how block chain and crypto currency can revolutionize business", Business Horizons, Vol. 62 No. 6, pp. 773-784.

Leland, H.E. and Pyle, D.H. (1977), "Informational asymmetries, financial structure and financial intermediation", The Journal of Finance, Vol. 32 No. 2, pp. 371-387.

Li, Z., Zhong, R.Y., Tian, Z.G., Dai, H.N., Barenji, A.V. and Huang, G.Q. (2021a), "Industrial block chain: a state-of-the-art survey", Robotics and Computer-Integrated Manufacturing, Vol. 70, p. 102124.

Li, J.P., Naqvi, B., Rizvi, S.K.A. and Chang, H.L. (2021b), "Bitcoin: the biggest financial innovation of fourth industrial revolution and a portfolio's efficiency booster", Technological Forecasting and Social Change, Vol. 162, p. 120383.

Linton, J.D. (2018), “Open innovation/integration versus disintermediation/disintegration”, Technovation, Vol. 78, pp. 1-3.

Liu, L., Tsai, W.T., Bhuiyan, M.Z.A. and Yang, D. (2020), "Automatic block chain whitepapers analysis via heterogeneous graph neural network", Journal of Parallel and Distributed Computing, Vol. 145, pp. 1-12.

Mazzella, F., Sundararajan, A., d’Espous, V.B. and Möhlmann, M. (2016), "How digital trust powers the sharing economy", IESE Business Review, Vol. 26 No. 5, pp. 24-31.

Mendling, J., Weber, I., Aalst, W.V.D., Brocke, J.V., Cabanillas, C., Daniel, F., Debois, S., Ciccio, C.D., Dumas, M., Dustdar, S., Gal, A. and Zhu, L. (2018), "Blockchains for business process management-challenges and opportunities", ACM Transactions on Management Information Systems (Systems), Vol. 9 No. 1, pp. 1-16.

Meralli, S. (2020), "Privacy-preserving analytics for the securitization market: a zero-knowledge distributed ledger technology application”, Financial Innovation, Vol. 6 No. 1, p. 7.

Merton, R.C. (1995), "A functional perspective of financial intermediation”, Financial Management, Vol. 24 No. 2, pp. 23-41.

Moretto, A., Grassi, L., Caniato, F., Giorgino, M. and Ronchi, S. (2019), "Supply chain finance: from traditional to supply chain credit rating", Journal of Purchasing and Supply Management, Vol. 25 No. 2, pp. 197-217.

Morgan, D.L. (1996), Focus Groups as Qualitative Research, Sage publications, Vol. 16.

Nakamoto, S. (2008), "Bitcoin: a peer-to-Peer electronic cash system”, available at https://bitcoin.org/ bitcoin.pdf (accessed 25 February 2021).

Nath, N., Othman, R. and Laswad, F. (2019), "External performance audit in New Zealand public health: a legitimacy perspective”, Qualitative Research in Accounting and Management, Vol. 17 No. 2, pp. 145-175.

Nilsson, A. and Öhman, P. (2012), "Better safe than sorry: defensive loan assessment behaviour in a changing bank environment", Qualitative Research in Accounting and Management, Vol. 9 No. 2, pp. 146-167.

Njegomir, V. and Miškić, M. (2018), "Insurance companies' financial intermediation”, Civitas, Vol. 8 No. 1, p. 47. 
QRAM 19,3

Nofer, M., Gomber, P., Hinz, O. and Schiereck, D. (2017), "Blockchain”, Business and Information Systems Engineering, Vol. 59 No. 3, pp. 183-187.

Notheisen, B., Cholewa, J.B. and Shanmugam, A.P. (2017), “Trading real-world assets on block chain”, Business and Information Systems Engineering, Vol. 59 No. 6, pp. 425-440.

Novo, O. (2018), "Block chain meets IOT: an architecture for scalable access management in IOT", IEEE Internet of Things Journal, Vol. 5 No. 2, pp. 1184-1195.

Perlman, L. (2019), "Regulation of the financial components of the Crypto-Economy", SIPA's Entrepreneurship and Policy Initiative Working Paper Series.

Regner, F. Urbach, N. and Schweizer, A. (2019), "NFTs in practice-non-fungible tokens as core component of a block chain-based event ticketing application".

Rindfleisch, A. and Heide, J.B. (1997), "Transaction cost analysis: past, present and future applications", Journal of Marketing, Vol. 61 No. 4, pp. 30-54.

Roth, A.E. (2015), Who Gets What - and Why: The New Economics of Matchmaking and Market Design, Houghton Mifflin Harcourt.

Rubinstein, A. and Wolinsky, A. (1987), "Middlemen”, The Quarterly Journal of Economics, Vol. 102 No. 3, pp. 581-593.

Saberi, S., Kouhizadeh, M., Sarkis, J. and Shen, L. (2019), "Block chain technology and its relationships to sustainable supply chain management", International Journal of Production Research, Vol. 57 No. 7, pp. 2117-2135.

Santoso, W., Sitorus, P.M., Batunanggar, S., Krisanti, F.T., Anggadwita, G. and Alamsyah, A. (2021), "Talent mapping: a strategic approach toward digitalization initiatives in the banking and financial technology (FinTech) industry in Indonesia”, Journal of Science and Technology Policy Management, Vol. 12 No. 3, pp. 399-420.

Schär, F. (2021), "Decentralized finance: on block chain-and smart contract-based financial markets", Review, Vol. 103 No. 2, pp. 153-174.

Schmidt, R.H., Hackethal, A. and Tyrell, M. (1999), "Disintermediation and the role of banks in Europe: an international comparison”, Journal of Financial Intermediation, Vol. 8 Nos 1/2, pp. 36-67.

Schmitz, J. and Leoni, G. (2019), "Accounting and auditing at the time of block chain technology: a research agenda", Australian Accounting Review, Vol. 29 No. 2, pp. 331-342.

Schwartz, R.A. and Peng, L. (2013), "Market makers”, Encyclopedia of Finance, pp. 487-489.

Selgin, G. (2015), “Synthetic commodity money”, Journal of Financial Stability, Vol. 17, pp. $92-99$.

Shiller, R.J. (2013), Finance and the Good Society, Princeton University Press.

Sumarwan, A., Luke, B. and Furneaux, C. (2021), "Putting members in the Centre: examining credit union accountability as member-based social enterprises", Qualitative Research in Accounting and Management, doi: 10.1108/QRAM-11-2019-0126.

Suryono, R.R., Budi, I. and Purwandari, B. (2021), "Detection of fintech P2P lending issues in Indonesia", Heliyon, Vol. 7 No. 4, p. e06782.

Swan, M. and De Filippi, P. (2017), "Toward a philosophy of block chain: a symposium: Introduction", Metaphilosophy, Vol. 48 No. 5, pp. 603-619.

Tapscott, A. and Tapscott, D. (2017), "How blockchain is changing finance", Harvard Business Review, Vol. 1 No. 9, pp. 2-5.

Thakor, A.V. (2020), "Fintech and banking: what do we know?", Journal of Financial Intermediation, Vol. 41, p. 100833.

Tien, S.K., Wang, Y.T., Cai, Y.Z. and Tsai, M.H. (2020), "Maximizing the time value of crypto currency in smart contracts with decentralized money markets", 2020 IEEE International Conference on Blockchain (Blockchain), IEEE, pp. 503-508.

Toapanta, S.M.T., Monteverde, A.A.C., Rojas, J.G.O. and Gallegos, L.E.M. (2019), "Proposal of ledger technology to apply to a public organization in Ecuador", Advances in Science, Technology and Engineering Systems Journal, Vol. 4 No. 3, pp. 251-259. 
Umar, M., Rizvi, S.K.A. and Naqvi, B. (2021), "Dance with the devil? The nexus of fourth industrial revolution, technological financial products and volatility spillovers in global financial system", Technological Forecasting and Social Change, Vol. 163, p. 120450.

Wang, J., Li, M., He, Y., Li, H., Xiao, K. and Wang, C. (2018), “A block chain based privacy-preserving incentive mechanism in crowd sensing applications”, IEEE Access, Vol. 6, pp. 17545-17556.

Wang, R., Lin, Z. and Luo, H. (2019), "Block chain, bank credit and SME financing”, Quality and Quantity, Vol. 53 No. 3, pp. 1127-1140.

Weber, B. (2016), "Bitcoin and the legitimacy crisis of money", Cambridge Journal of Economics, Vol. 40

Do we still need financial intermediation? No. 1, pp. 17-41.

Werner, S.M. Perez, D. Gudgeon, L. Klages-Mundt, A. Harz, D. and Knottenbelt, W.J. (2021), "SoK: Decentralized finance (DeFi)", arXiv preprint arXiv:2101.08778.

Westerkamp, M., Victor, F. and Küpper, A. (2020), "Tracing manufacturing processes using block chainbased token compositions", Digital Communications and Networks, Vol. 6 No. 2, pp. 167-176.

Williamson, O.E. (1979), "Transaction-cost economics: the governance of contractual relations", The Journal of Law and Economics, Vol. 22 No. 2, pp. 233-261.

Williamson, O.E. (1981), "The economics of organization: the transaction cost approach", American Journal of Sociology, Vol. 87 No. 3, pp. 548-577.

Williamson, O.E. (1985), The Economic Institutions of Capitalism, Free Press, New York, NY.

Williamson, O.E. (1991), "Comparative economic organization: the analysis of discrete structural alternatives", Administrative Science Quarterly, Vol. 36 No. 2, pp. 269-296.

Wong, C.Y. and Eng, Y.K. (2020), "P2P finance and the effectiveness of monetary controls", The Manchester School, Vol. 88 No. 4, pp. 617-639.

Wüst, K. and Gervais, A. (2018), "Do you need a block chain?”, 2018 Crypto Valley Conference on Blockchain Technology (CVCBT), IEEE, pp. 45-54.

Yang, J., Bi, H., Liang, Z., Zhou, H. and Yang, H. (2020), "A survey on block chain: architecture, applications, challenges and future trends", 2020 International Conferences on Internet of Things (iThings) and IEEE Green Computing and Communications (GreenCom) and IEEE Cyber, Physical and Social Computing (CPSCOM) and IEEE Smart Data (SmartData) and IEEE Congress on Cybermatics (Cybermatics), IEEE, pp. 749-754.

Yermack, D. (2017), "Corporate governance and block chains”, Review of Finance, Vol. 21 No. 1, pp. 7-31.

Yip, A.W. and Bocken, N.M. (2018), "Sustainable business model archetypes for the banking industry", Journal of Cleaner Production, Vol. 174, pp. 150-169.

Zavolokina, L., Dolata, M. and Schwabe, G. (2016), "FinTech transformation: how IT-Enabled innovations shape the financial sector", Proceedings in International Workshop on Enterprise Applications and Services in the Finance Industry, pp. 75-88.

Zetzsche, D.A., Arner, D.W. and Buckley, R.P. (2020), "Decentralized finance", Journal of Financial Regulation, Vol. 6 No. 2, pp. 172-203.

Zhang, S., Aerts, W., Lu, L. and Pan, H. (2019), "Readability of token whitepaper and ICO first-day return”, Economics Letters, Vol. 180, pp. 58-61.

\section{Corresponding author}

Laura Grassi can be contacted at: laura.grassi@polimi.it

For instructions on how to order reprints of this article, please visit our website:

www.emeraldgrouppublishing.com/licensing/reprints.htm

Or contact us for further details: permissions@emeraldinsight.com 